\title{
Share - Workpackage 5: evidence based recommendations for diagnosis and treatment of juvenile idiopathic arthritis
}

\author{
Sebastiaan Vastert ${ }^{1 *}$, Victor Boom ${ }^{1}$, Angelo Ravelli ${ }^{2}$, Alberto Martini ${ }^{2}$, Helen Foster ${ }^{3}$, Nico Wulffraat ${ }^{1}$, \\ SHARE JIA Experts, Jordi Anton', Tamas Constantin', Pavla Dolezalova ${ }^{1}$, Gerd Horneff', Pekka Lahdenne', \\ Bo Magnussen ${ }^{1}$, Kirsten Minden ${ }^{1}$, Kiran Nistala', Pierre Quartier ${ }^{1}$, Ingrida Rumbla ${ }^{1}$, Nicola Ruperto ${ }^{1}$, \\ Vanessa Remy Piccolo', Ricardo Russo', Sefi Uziel', C Wouters ${ }^{1}$
}

From 21st European Pediatric Rheumatology (PReS) Congress

Belgrade, Serbia. 17-21 September 2014

\section{Introduction}

Juvenile Idiopathic Arthritis (JIA) is one of the most common chronic pediatric rheumatic diseases (PRD). As is the case for most PRD's, evidence-based guidelines are sparse and management is based to great extent on physician's experience. Moreover, there are differences between nations regarding availability and financing of biological therapies. Consequently, treatment regimens differ throughout Europe. In 2012, a European initiative called SHARE (Single Hub and Access point for pediatric Rheumatology in Europe) was launched to optimize and disseminate diagnostic and management regimens in Europe for children and young adults with rheumatic diseases.

\section{Objectives}

To provide evidence based recommendations for diagnosis and treatment of JIA.

\section{Methods}

Evidence based recommendations were developed using the European League Against Rheumatism (EULAR) standard operating procedure [1]. An expert committee was instituted, consisting of pediatric rheumatologists from across Europe with expertise in JIA. The expert committee defined search terms for the systematic literature review. Two independent experts scored articles for validity and level of evidence. Recommendations derived from the literature were evaluated by an online

\section{Table 1}

\begin{tabular}{cc}
\hline & Juvenile idiopathic arthritis \\
\hline Diagnosis & Treatment \\
\hline The value of MRI in the diagnosis arthritis & Steroids (locally and systemically administered) \\
\hline The value of ultrasound in the diagnosis of arthritis & DMARDS \\
\hline Biomarkers for diagnosis of JIA & Biologicals \\
\hline Diagnosis of complications & Treatment of complications \\
\hline
\end{tabular}

'Pediatric Rheumatology, University Medical Center, Utrecht, Netherlands Full list of author information is available at the end of the article 
survey. Those with less than $80 \%$ agreement during the online survey were reformulated. Subsequently, all recommendations were discussed by the experts at a consensus meeting using the nominal group technique [2]. Recommendations were accepted if more than $80 \%$ agreement was reached.

\section{Results}

The literature search yielded 4723 articles, of which 174 were considered relevant. The included articles were scored for validity and level of evidence. Recommendations were formulated based on the valid papers and were discussed and adjusted where needed during the consensus meeting. In total, 10 recommendations for diagnosis and 31 for treatment were accepted with more than $80 \%$ agreement. Topics covered for diagnosis and for treatment are shown in Table 1.

\section{Conclusion}

The SHARE initiative provides recommendations for diagnosis and treatment of JIA and thereby facilitates improvement and uniformity of care throughout Europe. In the subsequent phase of the project, best practices identified from literature will be completed with the 'experts opinion' in order to formulate diagnostic and management guidelines as best practices for care of JIA patients throughout Europe.

\section{Disclosure of interest}

S. Vastert Consultant for: Novartis, V. Boom: None Declared, A. Ravelli: None Declared, A. Martini: None Declared, H. Foster: None Declared, N. Wulffraat Grant / Research Support from: Abbvie, GSK, Roche, Consultant for: Novartis, Genzyme, Roche, Pfizer.

\section{Authors' details}

'Pediatric Rheumatology, University Medical Center, Utrecht, Netherlands.

${ }^{2}$ Pediatric Rheumatology, G Gaslini Institute, Genua, Italy. ${ }^{3}$ Pediatric

Rheumatology, The Medical School, Newcastle University, Newcastle, UK.

Published: 17 September 2014

\section{References}

1. Dougados, et al: Annals of the Rheumatic Diseases 2004

2. de Ven, et al: American Journal of Public Health 1972.

doi:10.1186/1546-0096-12-S1-P171

Cite this article as: Vastert et al.: Share - Workpackage 5: evidence based recommendations for diagnosis and treatment of juvenile idiopathic arthritis. Pediatric Rheumatology 2014 12(Suppl 1):P171.

\section{Submit your next manuscript to BioMed Central} and take full advantage of:

- Convenient online submission

- Thorough peer review

- No space constraints or color figure charges

- Immediate publication on acceptance

- Inclusion in PubMed, CAS, Scopus and Google Scholar

- Research which is freely available for redistribution

Submit your manuscript at www.biomedcentral.com/submit 